\title{
Juglone reduces growth and migration of U251 glioblastoma cells and disrupts angiogenesis
}

\author{
JIAN WANG ${ }^{1}, \mathrm{KE} \mathrm{LIU}^{2}$, XIAO-FENG WANG ${ }^{2}$ and DIAN-JUN SUN ${ }^{3}$ \\ ${ }^{1}$ Department of Neurosurgery, The Fourth Affiliated Hospital of Harbin Medical University, Harbin, Heilongjiang; \\ ${ }^{2}$ Department of Oral and Maxillofacial Surgery, The Second Affiliated Hospital of Harbin Medical University, \\ Harbin, Heilongjiang; ${ }^{3}$ Key Laboratory of Etiology and Epidemiology, Education Bureau of Heilongjiang \\ Province and Ministry of Health, Center for Endemic Disease Control, Chinese Center for Disease \\ Control and Prevention, Harbin Medical University, Harbin, Heilongjiang 150081, P.R. China
}

Received January 28, 2017; Accepted June 21, 2017

DOI: $10.3892 /$ or.2017.5878

\begin{abstract}
Accumulating data show that prolylisomerase (Pin1) is overexpressed in human glioblastoma multiforme (GBM) specimens. Therefore, Pin1 inhibitors should be investigated as a new chemotherapeutic drug that may enhance the clinical management of human gliomas. Recently, juglone, a Pin1 inhibitor, was shown to exhibit potent anticancer activity in various tumor cells, but its role in human glioma cells remains unknown. In the present study, we determined if juglone exerts antitumor effects in the U251 human glioma cell line and investigated its potential underlying molecular mechanisms. Cell survival, apoptosis, migration, angiogenesis and molecular targets were identified with multiple detection techniques including the MTT cell proliferation assay, dual acridine orange/ethidium bromide staining, electron microscopy, Transwell migration assay, chick chorioallantoic membrane assay, quantitative real-time polymerase chain reaction and immunoblotting. The results showed that 5-20 $\mu \mathrm{M}$ juglone markedly suppressed cell proliferation, induced apoptosis, and enhanced caspase-3 activity in U251 cells in a dose- and timedependent manner. Moreover, juglone inhibited cell migration and the formation of new blood vessels. At the molecular level, juglone markedly suppressed Pin1 levels in a time-dependent manner. TGF- $\beta 1 / \mathrm{Smad}$ signaling, a critical upstream regulator of miR-21, was also suppressed by juglone. Moreover, the transient overexpression of Pin1 reversed its antitumor effects in U251 cells and inhibited juglone-mediated changes to the
\end{abstract}

Correspondence to: Dr Xiao-Feng Wang, Department of Oral and Maxillofacial Surgery, The Second Affiliated Hospital of Harbin Medical University, Harbin, Heilongjiang 150081, P.R. China E-mail:m1363367165@163.com

Dr Dian-Jun Sun, Key Laboratory of Etiology and Epidemiology, Education Bureau of Heilongjiang Province and Ministry of Health, Center for Endemic Disease Control, Chinese Center for Disease Control and Prevention, Harbin, Heilongjiang 150081, P.R. China E-mail: hrbmusdj@163.com

Key words: juglone, Pin1, TGF- $\beta 1$, miR-21, glioma
TGF- $\beta 1 /$ miR-21 signaling pathway. These findings suggest that juglone inhibits cell growth by causing apoptosis, thereby inhibiting the migration of U251 glioma cells and disrupting angiogenesis; and that Pin1 is a critical target for juglone's antitumor activity. The present study provides evidence that juglone has in vitro efficacy against glioma. Therefore, additional studies are warranted to examine the clinical potential of juglone in human gliomas.

\section{Introduction}

Glioblastoma multiforme (GBM), which develops from astrocytes, is the most malignant primary brain tumor in adults. Classified as a grade IV (most serious) astrocytoma, it has one of the worst prognoses among all human tumors, with a median survival of approximately 12 months (1). Chemoprevention to prevent glioma progression in patients after surgery is an important strategy, but glioma resistance to chemotherapy has been one of the major obstacles to successful anticancer therapy (2). Chemotherapeutic agents, such as doxorubicin, paclitaxel and 5-fluorouracil, clearly have some degree of activity in tumor treatment, but did not increase the median overall survival in patients with gliomas (3). Thus, it is clearly necessary to determine the molecular mechanisms underlying malignant tumor progression and resistance to treatment, with the goal of developing chemotherapies based on more effective clinical therapies.

Pin1 is a peptidylprolylcis/transisomerase (PPIase) that catalyzes the isomerization of the peptide bond between phospho-serine/threonine and proline $(4,5)$. Previous reports have indicated that it plays a critical role in Alzheimer's disease, adipogenesis and malignant tumor formation (4). Recently, it was reported that Pin1 protein expression was upregulated in human GBM specimens $(6,7)$; thus, it is necessary to determine if Pin1 inhibitors have chemotherapeutic potential in this disease. Juglone (5-hydroxy-1,4-napthoquinone) is a natural compound isolated from Juglans mandshurica Maxim (8). Several studies have shown that it has various pharmacological effects such as anti-viral, anti-bacterial and anticancer properties $(9,10)$. Moreover, many experiments have demonstrated that it irreversibly inhibits the enzymatic 
activity of Pin1 $(8,11,12)$. Thus, we hypothesized that juglone exerts its antitumor effects in glioma cells by suppressing Pin1-mediated signaling.

\section{Materials and methods}

Cell culture. The human glioblastoma cell line, U251, and human umbilical vein endothelial cells (HUVECs) were obtained from the China Academia Sinica Cell Repository (Shanghai, China). The cells were maintained in RPMI-1640 (Gibco, Grand Island, NY, USA) supplemented with 15\% fetal bovine serum (FBS; Gibco), 2 mM glutamine (Sigma-Aldrich, St. Louis, MO USA), 100 units/ml penicillin (Sigma-Aldrich), and $100 \mu \mathrm{g} / \mathrm{ml}$ streptomycin (Sigma-Aldrich) and were incubated at $37^{\circ} \mathrm{C}$ with $5 \% \mathrm{CO}_{2}$.

Transfection. Cells were transfected with $1-\mu \mathrm{g} / \mathrm{ml}$ pc-DNA3.1-hPin1 plasmid (Genechem, Shanghai, China) using Lipofectamine ${ }^{\mathrm{TM}} 2000$ and were lysed after $48 \mathrm{~h}$.

MTT assay. U251 cells were seeded in a 96-well plate at a density of $2.5 \times 10^{4}$ cells/well and were allowed to adhere to the bottom of each well for $24 \mathrm{~h}$. After treatment, the medium in each well was removed and replaced with a phosphatebuffered saline (PBS) solution containing $5 \mathrm{mg} / \mathrm{ml}$ MTT, after which the plate was incubated at $37^{\circ} \mathrm{C}$ for $3 \mathrm{~h}$. Then, the remaining supernatant was removed, and $100 \mu 1$ dimethyl sulfoxide (DMSO) was added to each well and mixed thoroughly to dissolve the formazan crystals that developed. After $10 \mathrm{~min}$ of incubation to ensure, cell viability was determined by measuring the absorbance of each well at a wavelength of $570 \mathrm{~nm}$. Relative cell viability was expressed as the percentage of the treatment group relative to that of the control group.

Fluorescent microscopy measurements. U251 cells were seeded on a glass coverslip. After juglone (Sigma-Aldrich) treatment, the coverslips were treated with $20 \mu \mathrm{l}$ freshly prepared acridine orange/ethidium bromide $(\mathrm{AO} / \mathrm{EB})$ solution $(100 \mu \mathrm{g} / \mathrm{ml} \mathrm{AO}$ and $100 \mu \mathrm{g} / \mathrm{ml} \mathrm{EB}$ in PBS) and viewed under a fluorescence microscope (Olympus Corp., Tokyo, Japan). Cell images were captured with a charge-coupled device (CCD) digital camera (CoolSNAPcf; Roper Scientific, Tucson, AZ, USA). Apoptosis was identified using morphological criteria, including nuclear condensation and/or fragmentation.

Electron microscopy. To perform electron microscopy analysis, the U251 cells were fixed in $2.5 \%$ glutaraldehyde in PBS for $2 \mathrm{~h}$ at $4^{\circ} \mathrm{C}$ and post-fixed in $1 \%$ osmium tetroxide. After dehydration in a series of graded ethanol baths (30-100\%) and propylene oxide, cells were embedded in Epon. Cell sections (80-200 nm) were obtained using a Reichert UltraCut E microtome and stained with uranyl acetate. Grids were examined using a JEOL 1200 EXII electron microscope (JEOL Ltd., Tokyo, Japan).

Caspase-3 activity assay. Caspase-3 activity was determined with colorimetric assay kits (Sigma-Aldrich) according to the manufacturer's instructions. U251 cells were scraped from the plates in ice-cold PBS and lysed in $160 \mu 1$ ice-cold cell lysis buffer for $30 \mathrm{~min}$. The lysate was centrifuged at $13,000 \mathrm{x}$ g for
$30 \min$ at $4^{\circ} \mathrm{C}$, and the supernatant was used for subsequent assays. The fluorogenic substrates for caspase-3 were labeled with the fluorochrome 7-amino-methyl coumarin (AMC), which was released from these substrates upon cleavage by caspase-3. Enzyme activity was determined by monitoring the fluorescence produced by free AMC using a spectrofluorophotometer (RF-5301PC; Shimadzu Co., Kyoto, Japan) at $360 / 460 \mathrm{~nm}$. Caspase-3 activity was expressed in pmole AMC liberated per minute per microgram of protein.

Transwell migration assay. The Transwell migration and invasion assay was performed using 24-well cell culture inserts without Matrigel ( $8 \mu \mathrm{m}$ pore; BD Biosciences, San Jose, CA, USA). Briefly, $5 \times 10^{4}$ cells were re-suspended in $250 \mu 1$ serumfree RPMI-1640 and added to the inserts. A total volume of $500 \mu 1$ Dulbecco's modified Eagle's medium (DMEM) with $10 \%$ FBS was added to the lower chamber. After allowing cells to migrate for $4 \mathrm{~h}$ or invade for $22 \mathrm{~h}$, cells on the upper surface of the membrane were removed using a cotton swab, and the membranes were fixed in methanol and stained with crystal violet. The number of migrating or invading cells was determined by averaging the cell counts from nine randomly selected x100 fields.

Scratch wound healing assay. For the scratch wound healing assay, U251 cells were seeded at a density of $1 \times 10^{5}$ cells/6-well plate and allowed to grow overnight. After a 24-h treatment with juglone, a scratch wound was applied using a pipette tip, and a baseline image was obtained. Scratch wound closure was monitored over a 24 -h period. Wound healing and cell migration were quantified by measuring the distance between edges of the wound.

Chick chorioallantoic membrane assay. Chicken eggs were purchased from Heilongjiang Institute of Veterinary Science (Harbin, China) and maintained in a humidified $39^{\circ} \mathrm{C}$ incubator (Lyon Electric, Chula Vista, CA, USA). Pellets containing 0.5\% methylcellulose plus juglone $(200 \mu \mathrm{g})$ or control saline were placed onto the chick chorioallantoic membrane (CAM) of 10-day-old chick embryos. Eggs were subsequently incubated at $39^{\circ} \mathrm{C}$ and on day 13 , the CAM's were fixed, excised, and imaged using a digital camera (Canon PowerShot 6) attached to a stereo microscope (Carl Zeiss, Oberkochen, Germany). Angiogenesis was quantified by counting the branch points arising from tertiary vessels from a minimum of eight specimens from the three separate experiments.

Tube formation. To evaluate in vitro angiogenesis activity, tube formation assays were performed with HUVECs. Twenty-four-well plates were coated with $300 \mu 1$ Matrigel (Becton-Dickinson, Suzhou, China). HUVECs $\left(5 \times 10^{4}\right.$ cells $)$ were suspended in $500 \mu \mathrm{l}$ medium containing various concentrations of juglone, and added to the polymerized Matrigel. After incubation at $37^{\circ} \mathrm{C}$ for $6 \mathrm{~h}$, cells were fixed and stained with Diff-Quik II reagents (Dade Behring AG, Marburg, Germany), photographed and counted.

Western blot analysis. U251 cells were lysed in a buffer containing $50 \mathrm{mM}$ Tris- $\mathrm{HCl}$ (pH 7.4), $0.1 \mathrm{mM}$ phenylmethylsulfonyl fluoride and $5 \mathrm{mM}$ EGTA for extraction of cellular 
A

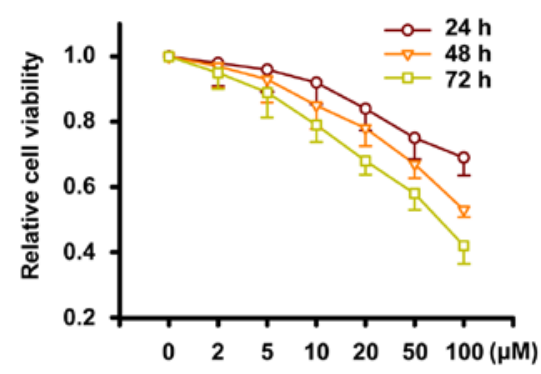

B
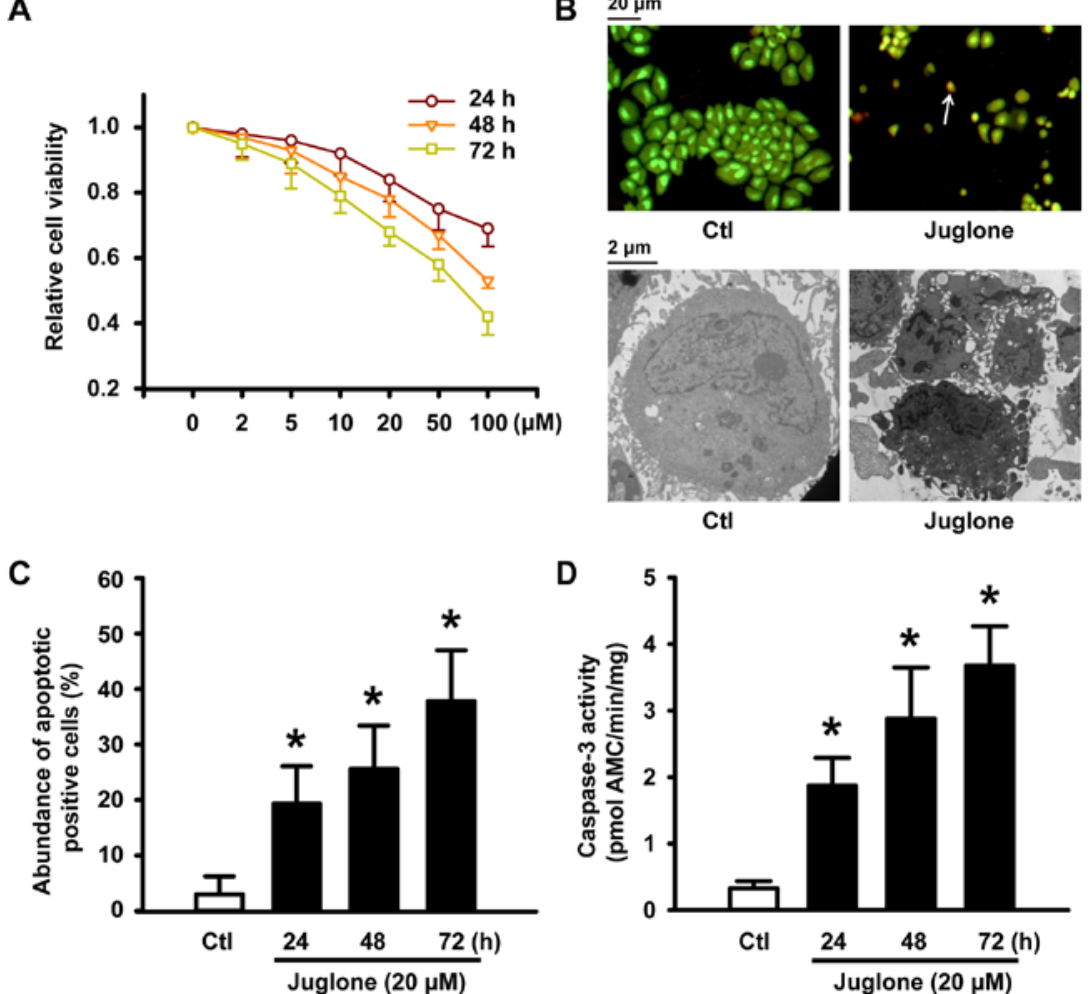

D

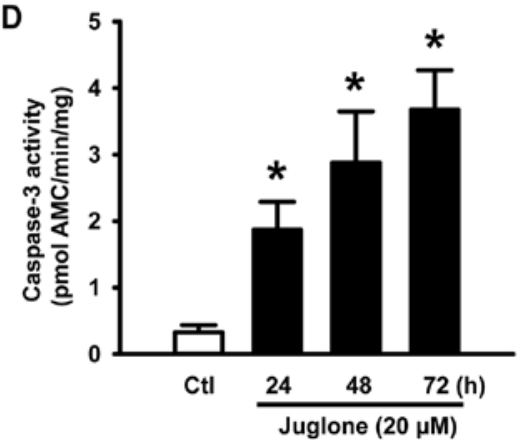

Figure 1. Juglone-induced reduction in cell viability and apoptosis in U251 cells. (A) U251 cells were treated with 2, 5, $10,20,50$ and $100 \mu \mathrm{M}$ juglone for 24,48 or $72 \mathrm{~h}$. Cell viability was detected by MTT assays. All of the assays were conducted in six replicates (n=6) for each treatment. Data are shown as mean \pm SD from three independent experiments. (B) U251 cells after exposure to $20 \mu \mathrm{M}$ juglone for 24,48 and $72 \mathrm{~h}$. Representative image of AO/EB staining (upper panel) and transmission electron microscopy (lower panel) of U251 cells treated with $20 \mu \mathrm{M}$ juglone for $48 \mathrm{~h}$. White arrows indicate apoptotic cells with morphological characteristics (chromatin condensation and nuclear shrinkage, original magnification, x100). Transmission electron microscopy showed characteristic changes of apoptosis in U251 cells treated with $20 \mu \mathrm{M}$ juglone for $48 \mathrm{~h}$ (chromosomal DNA condensation, segmentation of the nucleus, sunken nucleus membrane and loss of microvilli, original magnification, x8000). (C) Statistical bar graph of the abundance of apoptotic cells induced by juglone according to AO/EB staining. (D) Juglone enhanced the activity of caspase-3 by 7-amino-methyl coumarin assay. Data are shown as mean \pm SD of three independent experiments, ${ }^{*} \mathrm{P}<0.05$ vs. control.

proteins. Proteins (100 $\mu \mathrm{g} /$ lane) were resolved on $10 \%$ sodium dodecyl sulfate-polyacrylamide gel electrophoresis (SDS-PAGE) gels, and then electrophoretically transferred to nylon membranes. After blocking, the membranes were incubated overnight at $4^{\circ} \mathrm{C}$ with the appropriate rabbit polyclonal TGF- $\beta 1, \mathrm{p}-\mathrm{Smad} 2 / 3, \mathrm{Smad} 2 / 3$ (1:500 dilution; Abcam, Cambridge, UK), rabbit anti-VEGF antibody, or rabbit anti-CD31 antibodies (Proteintech, Wuhan, China). The goat anti-rabbit secondary antibody was from Invitrogen (Carlsbad, CA, USA). Western blot bands were quantified using Odyssey v1.2 software by measuring the band intensity (area $x$ OD) for each group and normalizing to GAPDH (anti-GAPDH antibody from Shanghai Kangcheng, Co., Ltd., Shanghai, China) served as the internal control.

TaqMan quantitative real-time PCR analysis of mature $m i R N A-21$. Total RNA isolated by TRIzol reagent (Invitrogen) was treated with the Turbo DNA-Free kit (Ambion, Austin, TX, USA) to eliminate genomic DNA contamination. TaqMan stem-loop real-time PCR was used to assess the expression of miR-21 using kits from Applied Biosystems (Foster City, $\mathrm{CA}, \mathrm{USA}$ ). In each sample, we calculated the $\Delta \mathrm{Ct}$ (targetreference). The fold-change between juglone-treated samples and the normal control for miR-21 was calculated with the $2^{-\Delta \Delta \mathrm{Ct}}$ method, in which $\Delta \Delta \mathrm{CT}=\Delta \mathrm{CT}$ (target-reference) (in juglone-treated samples) - $\Delta \mathrm{CT}$ (target reference) (in untreated samples). Quantitative real-time PCR (qPCR) was repeated in triplicate for each sample, and the average $2^{-\Delta \Delta C t}$ value and its standard deviation (SD) were calculated for each sample relative to the normal control for expression of miR-21. U6 and geNorm were used as reference genes to which the expression of miR-21 was normalized.

Statistical analysis. Data are presented as mean \pm SD. Statistical comparison was performed by the Student's t-test and analysis of variance (ANOVA). $\mathrm{P}<0.05$ were considered statistically significant.

\section{Results}

Juglone suppresses cell viability and induces apoptotic cell death of cultured U251 cells. After U251 glioma cells were treated with 5-100 $\mu \mathrm{M}$ juglone for 24, 48 and $72 \mathrm{~h}$, juglone gradually attenuated cell viability in a concentration- and time-dependent manner (Fig. 1A). To determine if the reduction in juglone-induced cell viability was due to apoptosis, $\mathrm{AO} / \mathrm{EB}$ staining and electron microscopy were performed to confirm the apoptotic changes. Fluorescence microscopic analysis showed that untreated U251 cells were stained with uniform green fluorescence (Fig. 1B, upper panel). Cells treated with $20 \mu \mathrm{M}$ juglone for $48 \mathrm{~h}$ showed clear morphological changes in the nucleolus, such as nuclear condensation 
A $50 \mu \mathrm{m}$

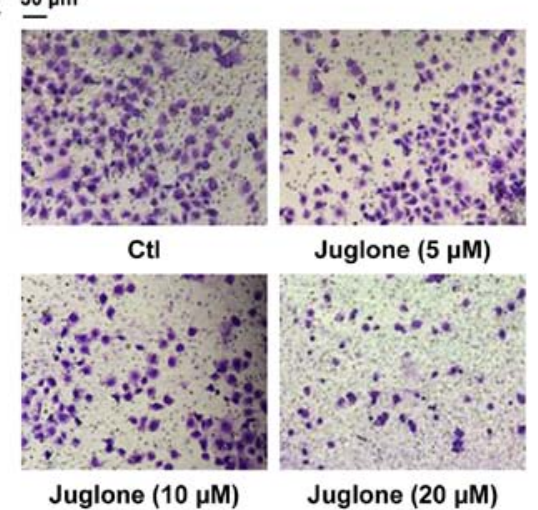

C $500 \mu \mathrm{m}$

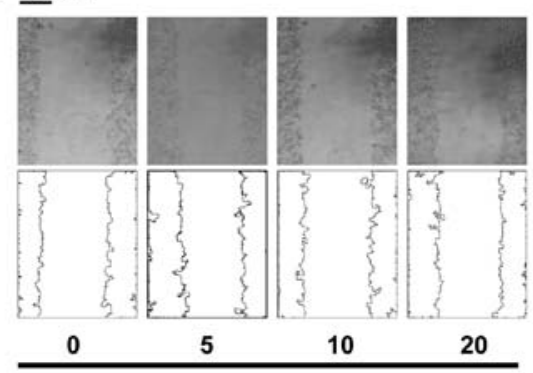

Juglone $(\mu \mathrm{M}) \mathrm{Oh}$

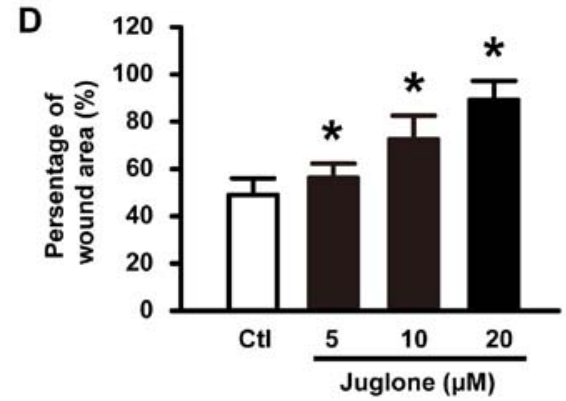

B
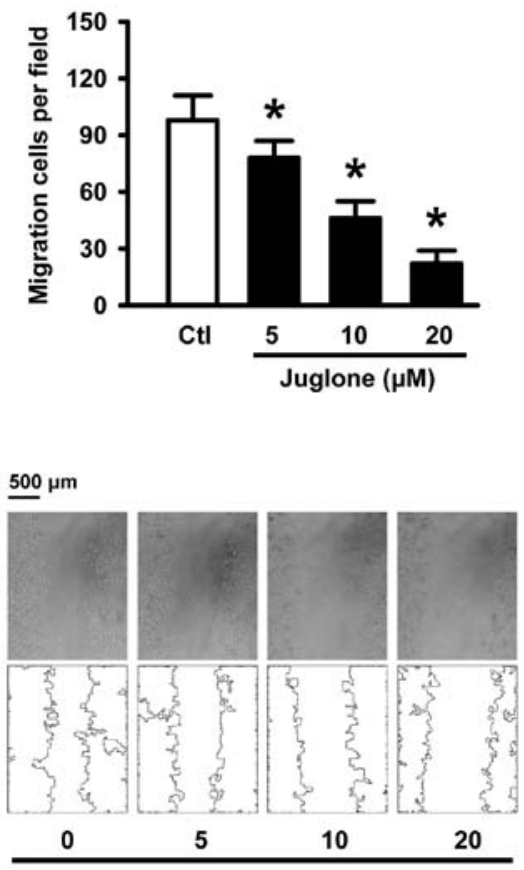

Juglone ( $\mu \mathrm{M}) 24 \mathrm{~h}$

Figure 2. Juglone inhibits the migration of U251 cells. U251 cells were treated with 5, 10 and $20 \mu \mathrm{M}$ juglone for $24 \mathrm{~h}$. Cells were subjected to Transwell $(\mathrm{A}$ and $\mathrm{B})$ and wound-healing assays $(\mathrm{C}$ and $\mathrm{D})$ to evaluate cell migration. Data are presented as mean \pm SD from three independent experiments. ${ }^{*} \mathrm{P}<0.05$ vs. control.

and/or fragmentation and orange apoptotic cells (indicated by arrows in Fig. 1B, upper panel). Juglone induced apoptosis of U251 cells in a time-dependent manner, and the number of apoptotic cells increased by $26 \%$ when cells were treated with $20 \mu \mathrm{M}$ of juglone for $48 \mathrm{~h}$ (Fig. 1C). We also examined the micromorphological changes induced by juglone using electron microscopy at an original magnification of $x 8,000$ as an alternative indication of apoptosis. As shown in Fig. 1B, the microstructure of the cell appeared normal under control conditions. However, cells treated with $20 \mu \mathrm{M}$ juglone for $48 \mathrm{~h}$ exhibited morphological changes in microstructure including chromosomal DNA condensation, segmentation of the nucleus, a sunken nucleus membrane and loss of microvilli. In addition, as shown in Fig. 1D (black bars), caspase-3 activity significantly increased after the treatment of U251 cells with $20 \mu \mathrm{M}$ juglone for 24,48 and $72 \mathrm{~h}$.

Juglone delays and decreases U251 cell migration in vitro. We further examined whether juglone affects cell migration ability in vitro. To this end, U251 cells were subjected to 5,
10 and $20 \mu \mathrm{M}$ juglone and their ability to migrate was evaluated with Transwell and wound healing assays. As shown in Fig. 2A and C, juglone significantly inhibited cellular transmigration ability in a dose-dependent manner compared to the controls. Quantitative analysis using ImageJ software also confirmed the significant anti-migratory effects of juglone at $24 \mathrm{~h}$ (Fig. 2B and D). These results strongly indicate that juglone may regulate the migration ability of the glioma cells.

The anti-angiogenesis role of juglone. Angiogenesis is a prerequisite for glioma tumor growth (13). The sprouting of endothelial cells and formation of tubes are crucial steps in the angiogenic process (14). We examined angiogenesis using the CAM assay. Compared with the controls, incubation with $200 \mu \mathrm{g}$ juglone directly inhibited formation of new blood vessels in the CAM (Fig. 3A and B). Control HUVECs spread and aligned with each other and formed a rich meshwork of branching anastomosing capillary-like tubules with multicentric junctions. This process was hardly influenced by $20 \mu \mathrm{M}$ juglone (Fig. 3C and D). Moreover, vascular endothelial 
A

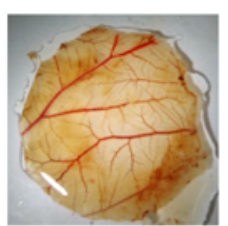

CtI

C

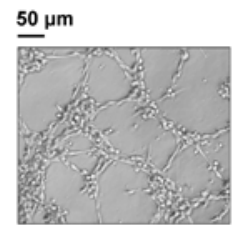

CtI
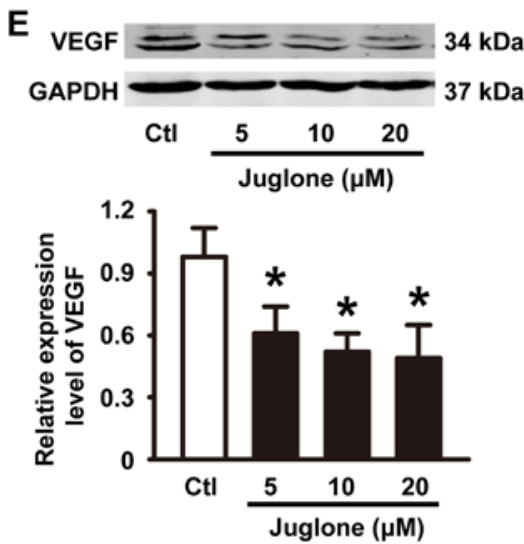

B

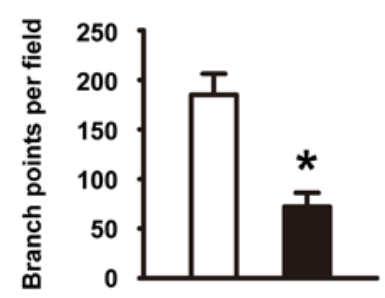

D

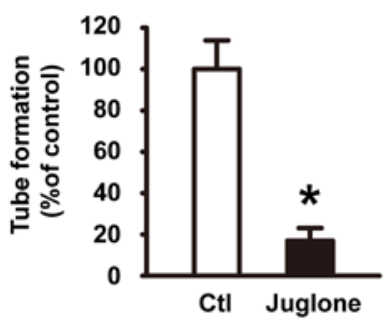

F
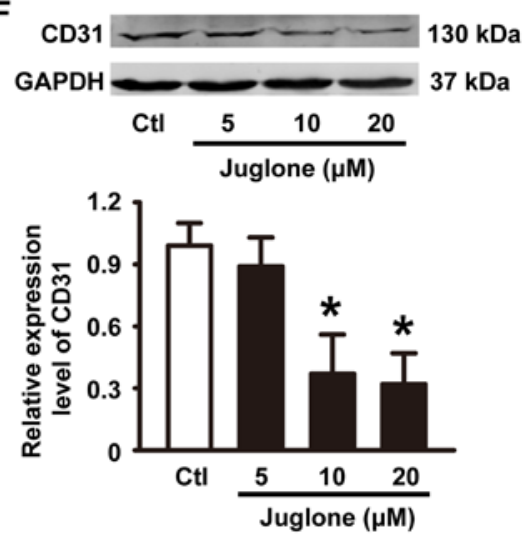

Figure 3. Juglone exerts anti-angiogenic activity. (A) Juglone inhibited new vessel growth in a CAM assay. (B) Quantitative bar graph of (A) showing branch points per field. $n=5$ independent experiments. (C and D) Julgone significantly suppressed tube formation of HUVECs in Matrigel (magnification, $\mathrm{x} 100$ ). $\mathrm{n}=6$ independent experiments. (E and F) HUVECs were incubated with juglone $(0,5,10$, or $20 \mu \mathrm{M})$ for $24 \mathrm{~h}$ and cell lysates were prepared. The expression of (E) VEGF and (F) CD31 in cell lysates was determined by western blot analysis. Anti-GAPDH was used as a loading control. Western blot band is a representative result from three independent experiments. ${ }^{*} \mathrm{P}<0.05$ vs. control.

growth factor (VEGF) and CD31, angiogenic markers, were detected by western blotting. Our experiments showed that treatment of HUVECs with juglone $(0,5,10$ and $20 \mu \mathrm{M})$ decreased VEGF and CD31 expression in a dose-dependent manner (Fig. 3E and F).

Juglone downregulates Pinl expression and inhibits the TGF- $\beta 1 / \mathrm{Smad} / \mathrm{miR}-21$ axis in U251 glioma cells. It has been suggested that Pin1 overexpression is associated with the development of glioma. Next, we performed western blotting to examine the expression of Pin1 in the absence and presence of juglone. As illustrated in Fig. 4A, 5-20 $\mu \mathrm{M}$ juglone led to a gradual decrease in Pin1 protein expression in a dose-dependent manner. Previous studies have shown that the TGF- $\beta / \mathrm{Smad} / \mathrm{miR}-21$ axis is implicated in glioma growth, migration and angiogenesis $(15,16)$. Importantly, Pin 1 is positive regulator of TGF- $\beta 1 \mathrm{mRNA}$ expression $(17,18)$ and the TGF- $\beta$ signaling pathway has been suggested to increase the level of miR-21 in a variety of cell types $(19,20)$. Thus, we tested the effects of juglone on TGF- $\beta, \operatorname{Smad} 2 / 3$ and miR-21 expression in U251 glioma cells. As expected, juglone significantly induced a decrease in TGF- $\beta 1$ mRNA (Fig. 4B) and protein expression (Fig. 4C), and the phosphorylation of its downstream signaling molecule Smad2/3 (Fig. 4D). Accordingly, qPCR analysis revealed that miR-21, as a TGF- $\beta$ downstream molecule, was downregulated in a dose-dependent manner with juglone treatment (Fig. 4E). These results suggest that the Pin1-associated TGF- $\beta 1 / \mathrm{Smad} 2 / 3 / \mathrm{miR}-21$ axis may play a role in juglone-mediated antitumor activity in cultured U251 glioma cells.

Transient overexpression of Pinl prevents julgone-induced antitumor effects. To further determine if Pin1 plays a critical role in the antitumor activity induced by juglone, we transfected human Pin1 plasmid into U251 cells. Successful transfection of Pin1 was verified (Fig. 5A). A statistical graph of apoptosis levels as determined by $\mathrm{AO} / \mathrm{EB}$ staining is shown in Fig. 5B. Incubation with $10 \mu \mathrm{M}$ juglone for $48 \mathrm{~h}$ caused an increase in the number of apoptotic cells compared to control cells. However, juglone-induced apoptosis was inhibited by Pin1 overexpression. Similarly, Pin1 overexpression also reduced the ability of juglone to block U251 migration (Fig. 5C and D). Accordingly, the inhibitory effects of juglone on TGF- $\beta 1$ and miR-21 expression were also reversed by Pin1 overexpression (Fig. 5E and F). These results suggest that Pin1 is a key target for juglone-mediated antitumor effects. 


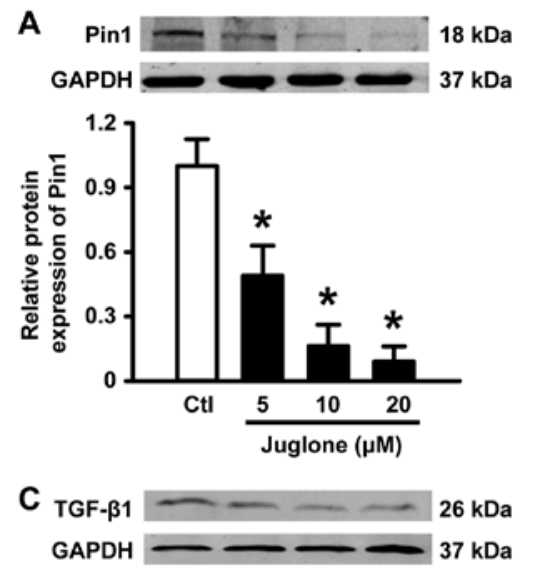

B
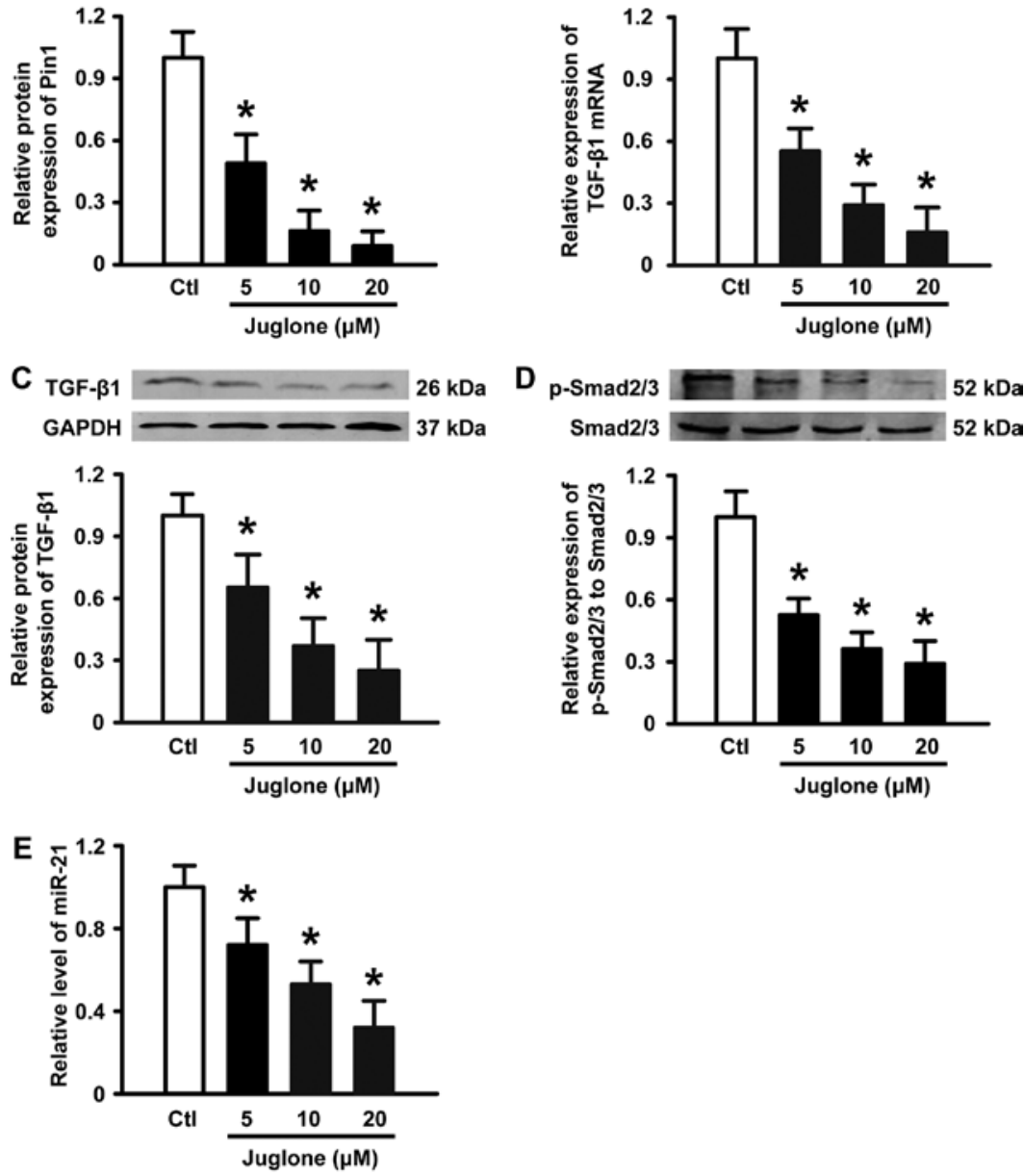

Figure 4. Effects of juglone on Pin1, TGF- $\beta 1$, Smad2/3 and miR-21 expression. U251 cells were treated with 5, 10 and $20 \mu \mathrm{M}$ juglone for $24 \mathrm{~h}$. (A) Western blot analysis of Pin1 in HUVECs with the indicated treatments. (B and C) Juglone-induced downregulation of TGF- $\beta$ mRNA and protein expression, as determined by qPCR and western blotting. (D) Juglone promoted a decrease in phospho-Smad2/3, as determined by western blotting. (E) Bar diagram summarizing the effects of juglone on miR-21 expression by qPCR. Data are shown as mean \pm SD of three independent experiments, ${ }^{*} \mathrm{P}<0.05$ vs. control.

\section{Discussion}

The present study clearly demonstrates that juglone, a Pin1 inhibitor, suppresses proliferation, induces apoptosis and migration of U251 glioma cells, and exerts anti-angiogenesis effects, thereby highlighting its therapeutic potential in glioma disease. The antitumor mechanisms of this naturally-occurring compound was associated with the downregulation of Pin1 expression and inhibition of downstream signaling molecules including TGF- $\beta 1$, Smad $2 / 3$ and miR-21, suggesting that Pin1 inhibition may be an attractive therapeutic target for glioma.

The unique role of Pin1 as a molecular switch that impacts multiple downstream pathways necessitates the evaluation of a highly specific Pin1 inhibitor to aid in potential therapeutic drug discovery. Recent data have indicated that juglone may be a useful antitumor agent for some cancer types. Accumulating data have indicated that juglone inhibits tumor cell growth through multiple functions such as cytotoxicity, induction of apoptosis and prevention of angiogenesis. For instance, $\mathrm{Hu}$ et al (11) revealed that juglone can effectively inhibit the proliferation, migration and angiogenic ability of MCF7Adr cells. Moreover, Fang et al (21) found that juglone induces apoptosis via the mitochondrial pathway and reduces cell invasiveness by decreasing matrix metalloproteinase (MMP) expression. Avc1 et al (22) demonstrated that juglone inhibits cell invasion and metastasis in a pancreatic cancer line. A report by Jha et al (23) indicated that juglone induces cell death of Acanthamoeba through increased production of reactive oxygen species. In the present study, we found that juglone $(5-20 \mu \mathrm{M})$ decreased the viability of cultured $\mathrm{U} 251$ glioma cells in a concentration- and time-dependent manner, which was accompanied by apoptosis, inhibition of cell migration and anti-angiogenesis activity. These results are consistent with previously published results showing that juglone inhibits the survival of many types of cultured cancer cells.

Many studies have shown that Pin1 is a major signaling molecule involved in the regulation of cellular proliferation, apoptosis, migration and angiogenesis (4). Notably, some studies have also shown that it is significantly overexpressed in glioma and correlates with malignant tumor progression and resistance to chemotherapy. For example, a report by Atabay et al (24) indicated that knockdown of Pin1 decreased the levels of VEGF and MMP-9 and reduced the angiogenic potential and tumorigenicity of glioblastoma cells. Similarly, 
A

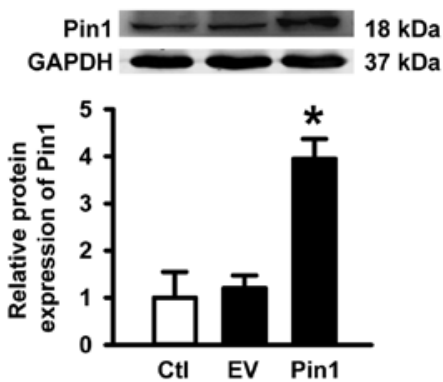

C

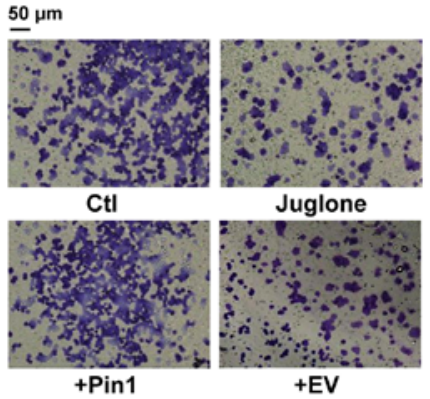

B

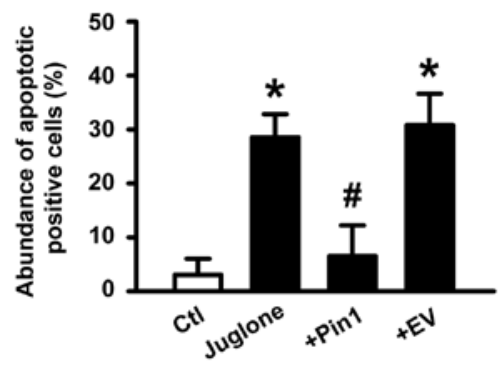

D

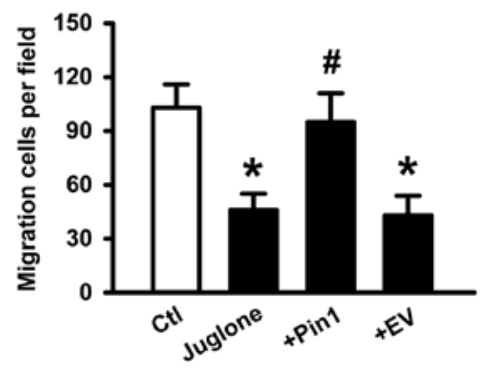

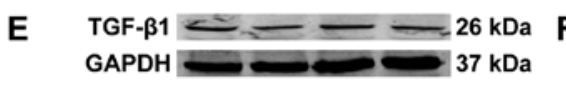
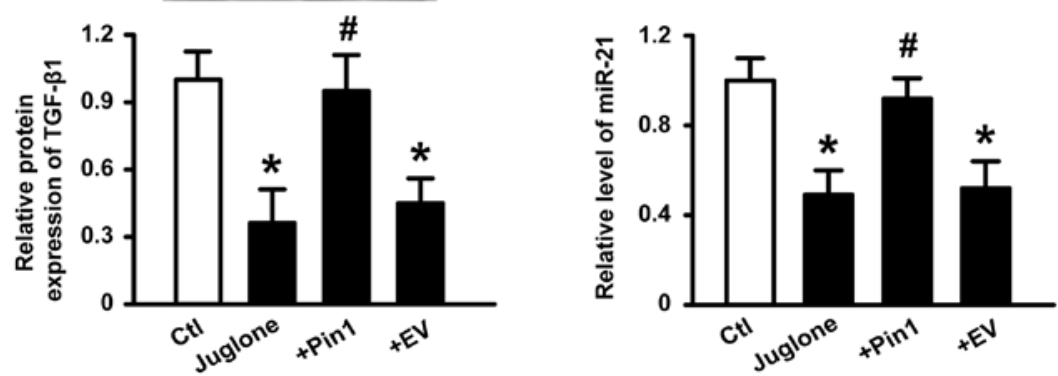

Figure 5. Effects of Pin1 overexpression on the antitumor activity of juglone. U251 cells were transfected with $1 \mu \mathrm{g} / \mathrm{ml}$ Pin 1 DNA or empty vector (EV, pc-DNA3.1 plasmid) (A) Pin1 expression determined by western blot analysis. Average band density from three independent experiments. "P<0.05 vs. control. (B) U251 cells were treated with $20 \mu \mathrm{M}$ juglone for $48 \mathrm{~h}$. The number of apoptotic cells as determined by the AO/EB assay. $\mathrm{n}=6$ independent experiments for each condition. (C and D) U251 cells were treated with $10 \mu \mathrm{M}$ juglone for $24 \mathrm{~h}$. Cells were subjected to Transwell migration assay. (E) TGF- $\beta$ protein expression, as determined by western blotting. (F) Bar diagram summarizing the effects of juglone on miR-21 expression as determined by qPCR. Data are shown as mean $\pm \mathrm{SD}$ of three independent experiments. ${ }^{*} \mathrm{P}<0.05$ vs. control, ${ }^{*} \mathrm{P}<0.05$ vs. cells treated with juglone.

Ryo et al (25) demonstrated that the targeted inhibition of Pin1 by small interfering RNA in A172 glioblastoma cells significantly enhanced the apoptotic response induced by hydrogen peroxide. These studies suggest that juglone may have chemotherapeutic potential in glioblastoma. To explain these observations at the molecular level, we evaluated the effects of juglone on Pin1 expression, and found that juglone reduced Pin1 protein expression in a dose-dependent manner, consistent with previous investigations. Shen et al (18) confirmed that Pin1 promotes the stability of TGF- $\beta 1$ mRNA by modulating the RNA-binding protein including AUF1, HuR and TIA-1 interaction with TGF- $\beta 1$ mRNA. Accordingly, in this context, after $24 \mathrm{~h}$ of juglone treatment, TGF- $\beta 1$ mRNA and protein levels were significantly reduced. These phenomena suggest that juglone can inhibit TGF- $\beta$ expression, probably due to its inhibitory effects on Pin1 activity.

In addition to tumor cells, juglone also affects other cells because Pin-1 has a key role in the regulation of many cell processes. For example, juglone can cause cell death in human fibroblasts (26), stimulate suicidal erythrocyte death or eryptosis (27), promote skin cell migration (9), alleviate myocardial fibrosis (28) and suppress cell adhesion to endothelial cells (29). In addition, juglone can also exert its effects in a Pin-1-independent manner, as was shown in a unilateral ureteral obstruction rat model in which juglone attenuated fibrogenesis. These antifibrotic effects may have resulted from the inhibition of Smad2 and oxidative stress (28).

It is generally recognized that miR-21 is a critical regulator for promoting the progression of malignant glioma. Recent results have indicated that it is upregulated in glioma vessels and subsets of glioma cells and exerts its anti-apoptotic effects by regulating programmed cell death (31). Hermansen et al (32) found that miR-21 co-localizes with the angiogenesis markers, HIF-1 $\alpha$ and VEGF, suggesting that it is correlated with glioma angiogenesis. We also confirmed that both VEGF and CD31 expression was downregulated in HUVECs upon exposure to juglone. Notably, Smad2/3, a downstream component of the TGF- $\beta$ signaling pathway, also controls DROSHA (also known as RNASEN) complex-mediated miR-21 maturation (19). Juglone also causes the downregulation of phospho-Smad $2 / 3$ protein expression. Notably, a report by Yang et al (17) demonstrated that TGF- $\beta 1$-induced Smad2/3 
phosphorylation is inhibited by Pin1 knockdown, indicating that decreased miR-21 expression induced by juglone might be due to inhibition of Pin1-related TGF- $\beta$ signaling. Most importantly, the transient overexpression of Pin1 inhibited the antitumor effects of juglone on U251 cells and reversed changes in the TGF- $\beta 1 / \mathrm{miR}-21$ signaling pathway that were induced by juglone. These data demonstrate that Pin1 plays a critical role in the antitumor effects of juglone.

In summary, the present study demonstrated that juglone inhibits Pin1 expression, thereby blocking TGF- $\beta 1 / \mathrm{Smad} /$ miR-21 signaling, suppressing U251 glioma cell growth and migration, and disrupting angiogenesis. These findings support the potential therapeutic effects of juglone in the treatment of glioma, although in vivo studies in animal models are needed.

\section{References}

1. Chen R, Cohen AL and Colman H: Targeted therapeutics in patients with high-grade gliomas: past, present, and future. Curr Treat Options Oncol 17: 42, 2016.

2. Levin VA, Tonge PJ,Gallo JM,Birtwistle MR, Dar AC,Iavarone A, Paddison PJ, Heffron TP, Elmquist WF, Lachowicz JE, et al: CNS Anticancer Drug Discovery and Development Conference White Paper. Neuro Oncol 17 (Suppl 6): vil-vi26, 2015.

3. Taal W, Bromberg JE and van den Bent MJ: Chemotherapy in glioma. CNS Oncol 4: 179-192, 2015.

4. Lu Z and Hunter T: Prolyl isomerase Pin1 in cancer. Cell Res 24: 1033-1049, 2014

5. La Montagna R, Caligiuri I, Giordano A and Rizzolio F: Pin1 and nuclear receptors: A new language? J Cell Physiol 228 1799-1801, 2013.

6. Atkinson GP, Nozell SE, Harrison DK, Stonecypher MS, Chen D and Benveniste EN: The prolyl isomerase Pin1 regulates the NF-kappaB signaling pathway and interleukin-8 expression in glioblastoma. Oncogene 28: 3735-3745, 2009.

7. Yang Y, Niu CS and Cheng CD: Pin1-Nanog expression in human glioma is correlated with advanced tumor progression. Oncol Rep 30: 560-566, 2013.

8. Costantino S, Paneni F, Lüscher TF and Cosentino F: Pin1 inhibitor Juglone prevents diabetic vascular dysfunction. Int J Cardiol 203: 702-707, 2016.

9. Wahedi HM, Park YU, Moon EY and Kim SY: Juglone ameliorates skin wound healing by promoting skin cell migration through Rac1/Cdc42/PAK pathway. Wound Repair Regen 24: 786-794, 2016

10. Wang J, Cheng Y, Wu R, Jiang D, Bai B, Tan D, Yan T, Sun X, Zhang $Q$ and Wu Z: Antibacterial activity of Juglone against Staphylococcus aureus: From apparent to proteomic. Int J Mol Sci 17. pii: E965. doi: 10.3390/ijms17060965.

11. Hu YG, Shen YF and Li Y: Effect of Pin1 inhibitor juglone on proliferation, migration and angiogenic ability of breast cancer cell line MCF7Adr. J Huazhong Univ Sci Technolog Med Sci 35: 531-534, 2015.

12. Kanaoka R, Kushiyama A, Seno Y, Nakatsu Y, Matsunaga Y, Fukushima T, Tsuchiya Y, Sakoda H, Fujishiro M, Yamamotoya T, et al: Pin1 inhibitor juglone exerts anti-oncogenic effects on LNCaP and DU145 cells despite the patterns of gene regulation by Pin1 differing between these cell lines. PLoS One 10 e0127467, 2015.

13. Schnoor R, Maas SL and Broekman ML: Heparin in malignant glioma: Review of preclinical studies and clinical results. J Neurooncol 124: 151-156, 2015.
14. Le Rhun E and Perry JR: Vascular complications in glioma patients. Handb Clin Neurol 134: 251-266, 2016.

15. Yu J, Cai X, He J, Zhao W, Wang Q and Liu B: Microarraybased analysis of gene regulation by transcription factors and microRNAs in glioma. Neurol Sci 34: 1283-1289, 2013.

16. Han J, Alvarez-Breckenridge CA, Wang QE and Yu J: TGF- $\beta$ signaling and its targeting for glioma treatment. Am J Cancer Res 5: 945-955, 2015.

17. Yang JW, Hien TT, Lim SC, Jun DW, Choi HS, Yoon JH, Cho IJ and Kang KW: Pin1 induction in the fibrotic liver and its roles in TGF- $\beta 1$ expression and Smad2/3 phosphorylation. J Hepatol 60: 1235-1241, 2014.

18. Shen ZJ, Esnault S, Rosenthal LA, Szakaly RJ, Sorkness RL, Westmark PR, Sandor M and Malter JS: Pin1 regulates TGF-beta1 production by activated human and murine eosinophils and contributes to allergic lung fibrosis. J Clin Invest 118: 479-490, 2008.

19. Davis BN, Hilyard AC, Lagna G and Hata A: SMAD proteins control DROSHA-mediated microRNA maturation. Nature 454: 56-61, 2008.

20. Zavadil J, Narasimhan M, Blumenberg $M$ and Schneider RJ: Transforming growth factor-beta and microRNA:mRNA regulatory networks in epithelial plasticity. Cells Tissues Organs 185: 157-161, 2007.

21. Fang F, Qin Y, Qi L, Fang Q, Zhao L, Chen S, Li Q, Zhang D and Wang L: Juglone exerts antitumor effect in ovarian cancer cells. Iran J Basic Med Sci 18: 544-548, 2015.

22. Avcı E, Arıkoğlu H and Erkoç Kaya D: Investigation of juglone effects on metastasis and angiogenesis in pancreatic cancer cells Gene 588: 74-78, 2016.

23. Jha BK, Jung HJ, Seo I, Suh SI, Suh MH and Baek WK: Juglone induces cell death of Acanthamoeba through increased production of reactive oxygen species. Exp Parasitol 159: 100-106, 2015.

24. Atabay KD, Yildiz MT, Avsar T, Karabay A and Kiliç T: Knockdown of Pin1 leads to reduced angiogenic potential and tumorigenicity in glioblastoma cells. Oncol Lett 10: 2385-2389, 2015.

25. Ryo A, Hirai A, Nishi M, Liou YC, Perrem K, Lin SC, Hirano H, Lee SW and Aoki I: A suppressive role of the prolyl isomerase Pin1 in cellular apoptosis mediated by the death-associated protein Daxx. J Biol Chem 282: 36671-36681, 2007.

26. Paulsen MT and Ljungman M: The natural toxin juglone causes degradation of $\mathrm{p} 53$ and induces rapid $\mathrm{H} 2 \mathrm{AX}$ phosphorylation and cell death in human fibroblasts. Toxicol Appl Pharmacol 209: $1-9,2005$

27. Calabrò S, Alzoubi K, Bissinger R, Jilani K, Faggio $\mathrm{C}$ and Lang F: Enhanced eryptosis following juglone exposure. Basic Clin Pharmacol Toxicol 116: 460-467, 2015.

28. Liu X, Liang E, Song X, Du Z, Zhang Y and Zhao Y: Inhibition of Pin1 alleviates myocardial fibrosis and dysfunction in STZ-induced diabetic mice. Biochem Biophys Res Commun 479: 109-115, 2016.

29. Liu M, Yu P, Jiang H, Yang X, Zhao J, Zou Y and Ge J: The essential role of Pin1 via NF-kappaB signaling in vascular inflammation and atherosclerosis in $\mathrm{ApoE}^{-/-}$mice. Int $\mathrm{J}$ Mol Sci 18: 644, 2017.

30. Reese S, Vidyasagar A, Jacobson L, Acun Z, Esnault S, Hullett D, Malter JS and Djamali A: The Pin 1 inhibitor juglone attenuates kidney fibrogenesis via Pin 1-independent mechanisms in the unilateral ureteral occlusion model. Fibrogenesis Tissue Repair 3: 1, 2010.

31. Wang G, Wang JJ, Tang HM and To SS: Targeting strategies on miRNA-21 and PDCD4 for glioblastoma. Arch Biochem Biophys 580: 64-74, 2015.

32. Hermansen SK, Nielsen BS, Aaberg-Jessen C and Kristensen BW: miR-21 is linked to glioma angiogenesis: A co-localization study. J Histochem Cytochem 64: 138-148, 2016. 